\title{
Validation of Nepalese Version of Utrecht Work Engagement Scale
}

\author{
Bimala PANTHEE ${ }^{1}$, Akihito SHIMAZU ${ }^{2,3}$ and Norito KAWAKAMI ${ }^{2}$ \\ ${ }^{1}$ Department of Psychiatric Nursing, Graduate School of Medicine The University of Tokyo, Japan, ${ }^{2}$ Department \\ of Mental Health, Graduate School of Medicine, The University of Tokyo, Japan and ${ }^{3}$ Asia Pacific Center for Work \\ Health Safety, University of South Australia, Australia
}

\begin{abstract}
Validation of Nepalese Version of Utrecht Work Engagement Scale: Bimala PAnthee, et al. Department of Psychiatric Nursing, Graduate School of Medicine, The University of Tokyo-Objective: The objective of the current study was to examine the psychometric properties of the Nepalese version of the Utrecht Work Engagement Scale (UWES-N) in a sample of hospital nurses. Method: Registered nurses from three hospitals in Nepal (total $\mathrm{N}=438$ ) voluntarily completed a self-administered paper-and-pencil questionnaire. Results: Confirmatory factor analysis revealed that the hypothesized three-factor model of the 9-item version of the UWES-N (UWES-N-9) fitted the data best. The internal consistency of the scale was acceptable. Work engagement was positively related to job satisfaction, job performance, happiness and health, and it was negatively related to psychological distress, confirming its construct validity. Conclusions: In conclusion, the findings of our study indicated that the UWES-N-9 has satisfactory psychometric properties and provided supportive evidence for use of the UWES$\mathrm{N}-9$ in the Nepalese context.
\end{abstract}

(J Occup Health 2014; 56: 421-429)

Key words: Utrecht work engagement scale, Validation, Work engagement

With the emergence of positive psychology, psychology became not only the study of pathology, weakness and damage but also the study of strength and virtue ${ }^{1)}$ to help people become stronger and more productive and increase their potential. Detecting such psychological strength is an important part of research and practice ${ }^{2)}$. Recently, work engagement has been identified as one of the positive states, as opposite

Received Feb 19, 2014; Accepted Jul 3, 2014

Published online in J-STAGE Sep 11, 2013

Correspondence to: N. Kawakami, Graduate School of Medicine, The University of Tokyo, 7-3-1 Hongo, Bunkyo-ku, Tokyo 113-0033, Japan (e-mail: nkawakami@m.u-tokyo.ac.jp) to burnout ${ }^{3)}$. Engaged workers have high levels of energy and identify strongly with their work ${ }^{4}$. Thus, work engagement is defined as a positive, fulfilling work-related state of mind that is characterized by vigor (i.e., high levels of energy and mental resilience while working, the willingness to invest effort in one's work and persistence even in the face of difficulties), dedication (i.e., a sense of significance, enthusiasm, inspiration, pride and challenge) and absorption (i.e., being fully concentrated and happily engrossed in one's work, whereby time passes quickly and one has difficulties detaching oneself from work) ${ }^{3)}$.

Previous studies found that work engagement has been positively associated with job satisfaction and quality of life $\mathrm{e}^{5)}$, happiness ${ }^{6)}$, health ${ }^{7}$, job performance and life satisfaction ${ }^{8)}$ and negatively associated with ill health $^{8)}$. To sum up, work engagement is associated with better well-being.

Before we can investigate work engagement, we need a valid measurement tool to accurately and consistently measure work engagement. The Utrecht Work Engagement Scale (UWES) ${ }^{3)}$ has been extensively studied to measure work engagement. The development of this scale was based on the theoretical definition of work engagement, which included three dimensions, vigor, dedication and absorption. Both long (17-item) and short (9-item) versions are available. The translated versions of the UWES, including the Dutch, Spanish, Chinese and Japanese versions, have been widely adopted in many international studies $^{3,9-11)}$. In addition, the scale has been shown to have acceptable psychometric properties across cultures $^{12)}$.

Nepal is a small developing country. For over a decade, it has been facing political instability, which has been directly influencing job security and economic uncertainty. In addition, the direct influence of politics on the work environment is another issue in Nepal. Despite the adverse work environ- 
ment, every organization seeks highly motivated and energetic (engaged) employees. Therefore, we believe that the time has come to follow the lead of positive psychology such as work engagement. As in other developed countries, the concept of work engagement might be fruitful for the study and practice of wellbeing among Nepalese workers. In order to study and apply the concept of work engagement in Nepal, the first step involves validation of the Nepali version of the UWES (UWES-N).

The objective of this current study was to examine the psychometric properties of the UWES-N. More specifically, we aimed (1) to evaluate the factorial validity by comparing the fit of the three-factor model to that of the one-factor model (which assumes that all items load on one single underlying dimension) for both the 17-item version and 9-item version of the UWES-N. Since the three dimensions are closely related, we chose the one-factor model (2) to examine the scale reliability using Cronbach's alpha, (3) to confirm the construct validity by examining the relationship between work engagement and its potential outcomes (psychological distress, overall health, job satisfaction, happiness and job performance) and (4) to explore the relation of work engagement with demographic characteristics. Overall, we hypothesized that the UWES-N will show adequate construct validity in the Nepalese context.

\section{Methods}

\section{Translation}

The translation procedure followed the established guideline $^{13)}$. First, two independent translators (a freelance translator and a member of the Nepal Notary Public Council) translated the English version of the Utrecht Work Engagement Scale (UWES) into Nepali. The first author of the current study (BP) compared the two independent forward translations and prepared the final forward translation into Nepali after discussion with the forward translators. Then, two independent bilingual persons (an individual with a medical degree and a researcher in the field of chemical biology) performed back-translation into English. We compared the original English and back-translated versions and created a preliminary Nepalese version after correcting some of the words, meanings and contents for each item in cooperation with the original developer of the UWES (WS). The preliminary version was tested in a pilot study with 20 Nepali participants who were working in Japan on a working visa. Some additional words and concepts were corrected after the pilot study. For instance, most participants were confused about the item "It is difficult to detach myself from my job" in the absorption subscale. The respondents preferred to know the reason for having difficulties in detaching themselves; therefore, one additional item was added, that is, "It is difficult to detach myself from my job because I enjoy my work", to see whether we could find any significant differences in the reasons behind the problem of detachment. The item was added to the end of the questionnaire.

\section{Participants}

The participants in this study were registered nurses in Nepal. As nurses are frontline service providers in the health-care system in Nepal and are generally present to their allocated place $(94 \%)$ in comparison with the doctors $(88 \%)^{14)}$, they have a crucial role in improving the health of the community. Therefore, it is most important to evaluate the well-being of nurses. Participation in this study was voluntary, and anonymity was guaranteed. We recruited nurses from three hospitals. Two hospitals were located in the capital city of Nepal (Kathmandu) (Central Development Region), and one hospital was located in the Western Development Region of Nepal (Rupandehi). In total, we distributed 587 questionnaires and received 455 back, giving us a response rate of $77.5 \%$. Because of missing values on the key items, 438 questionnaires were used in the final analysis, representing a final response rate of $74.5 \%$ of the response rate. The mean age of the respondents was 30.85 years $(\mathrm{SD}=9.95)$, and the mean work experience was 9.41 years $(\mathrm{SD}=9.61)$.

All nurses/participants were informed about the objectives of this study via the nurse in charge of each department. Questionnaires along with envelopes were distributed and collected through each department in charge to maximize the response rate. In addition, the questionnaires were returned by the participants in sealed envelopes to ensure their privacy. Consent from participants was confirmed based on their voluntary completion and submission of the questionnaires. The ethics committee of The University of Tokyo, Nepal Health Research Council and the associated hospitals approved the study procedures before the study began.

\section{Measures}

Work engagement was assessed using the preliminary Nepalese Version of the Utrecht Work Engagement Scale (UWES-N) comprising three subscales/dimensions assessing vigor, dedication and absorption. Both long and short versions are available. The long version is a 17 -item scale, with 6 items measuring vigor, 5 items measuring dedication and 7 items measuring absorption. The short version is a 9-item scale consisting of 3 dimensions, vigor, dedication and absorption. Each dimension has 3 
items. All items are scored on a 7-point Likert scale ranging from 0 ("Never") to 6 ("Always") in both versions.

Job performance was assessed by a single item from the World Health Organization Health and Work Performance Questionnaire (HPQ) $)^{15}$, which asks the participants to rate their overall work performance during the past 30 days on a 0 - to 10-point Likert scale, with 0 indicating "Worst performance" and 10 indicating "Best performance".

Job satisfaction was assessed using a single item ${ }^{16)}$, i.e., "How satisfied are you with your job in general?" measured on a 5-point Likert scale, with 1 indicating "Extremely satisfied" and 5 indicating "Not satisfied at all".

Overall health was assessed using 1 self-constructed item, i.e., "In general, how would you say your health is?" measured on a scale from 1 "Excellent" to 5 "Poor".

Happiness was assessed by a single question ${ }^{17)}$, i.e., "Taking everything into account, how happy are you with your life?" measured on a 4-point Likert scale, with 1 indicating "Very unhappy" and 4 indicating "Very happy".

Psychological distress was assessed using a Nepalese version of psychological distress questionnaire $(\mathrm{k} 6)^{18)}$, with items measured on a 5-point Likert scale ranging from 1 indicating "Always" to 5 indicating "Never". This 6-item questionnaire assesses both anxiety and depression. Cronbach's alpha coefficient for this study sample was 0.81 .

Most constructs were measured with a single item. One of the reasons for using one-item questionnaires is the lack of availability of Nepalese versions of questionnaires.

\section{Statistical analysis}

Exploratory factor analysis, correlation analysis, reliability analysis and other descriptive analyses were conducted using SPSS version 21. Confirmatory factor analysis (CFA) of both the 17-item and 9-item versions of the UWES-N was performed in AMOS ${ }^{19)}$ version 21 using structural equation modeling (SEM) methods. Maximum likelihood estimation was used to examine goodness of fit of the models using the following criteria $^{20)}$ for goodness of fit indices: GFI $\geq 0.95$, AGFI $\geq 0.90$, PGFI $\geq 0.80$, TLI $\geq 0.90$, CFI $\geq 0.90$, RMSEA $\leq 0.08$ and a small AIC that would indicate a more parsimonious the model. Cronbach's alpha coefficients were calculated for overall engagement, vigor, dedication and absorption subscales. Since calculating Cronbach's alpha may not be sufficient for measuring the homogeneity of each item $^{21)}$, we also reported inter-item correlations.

\section{Results}

\section{Factor structure}

First, we employed exploratory factor analyses of both 17- and 9-item questionnaires. Principal axis factoring with promax rotation confirmed the existence of a three-factor structure in the 17-item version of the UWES-N (UWES-N-17) (Table 1) and a two-factor structure in the 9-item version of the UWES-N (UWES-N-9) (Table 2). The three factors in the UWES-N-17 and two factors in the UWES-N-9 with eigenvalues greater than one were extracted, accounting for 43.5 and $49.2 \%$ of the total variance, respectively. The correlation between an item added to the absorption subscale, "It is difficult to detach myself from my job because I enjoy my work", and the original item, "It is difficult to detach myself from my job", was 0.67 , which is marginally high. Therefore, we continued the analysis with the original 17 items. Though three factors emerged for the UWES-N-17, the factor structure was not consistent with that of the original version. For instance, 7 items loaded on the first factor, 5 items loaded on the second factor, and the remaining 5 items loaded on the third factor. Each factor consisted of items related to either vigor, dedication or absorption (i.e., no items related to vigor, dedication and absorption were loaded on their respective factor) (Table 1). However, the UWES-N-9 had a two-factor structure, with items measuring absorption (AB3, AB4, AB5 and dedication (DE2, DE3, DE4) loaded on the first factor and those measuring vigor (VI1, VI2, VI3) loaded on the second factor, except for one item for vigor (VI3), i.e., "When I get up in the morning, I feel like going to work", which loaded on both factors (loadings of 0.40 and 0.36 on factors 1 and 2, respectively) (Table 2). Consequently, we decided to test one-factor, two-factor and three-factor solutions by CFA.

Although we found different factor structures, with three factors for the UWES-N-17 and two factors for the UWES-N-9, we considered the concept and theory of work engagement to test the fit of these models so that the study results would be comparable to other international studies. Therefore, we assessed the fit of the three models (i.e., one-factor, two-factor and three-factor models). First, we assessed the fit of the one-factor model. All items loaded significantly on the latent factors of both the UWES-N-17 and UWES-N-9 $(p<0.001)$. Next, we assessed the fit of the two-factor model (i.e., absorption and dedication factor and vigor factor) of the 9-item version. We then tested the hypothesized three-factor solution for both the UWES-N-17 and UWES-N-9. As can be seen in Table 3, the three-factor solution fitted the data best for both the UWES-N-17 and UWES-N-9. 
Table 1. Factor loadings for the 17-item Nepalese version of the UWES (UWES-N-17) by exploratory factor analysis with the principal axis factoring method and promax rotation $(\mathrm{N}=438)$

\begin{tabular}{llrrr}
\hline SN & Item & \multicolumn{3}{c}{ Factors } \\
\cline { 3 - 5 } & & 1 & 2 & 3 \\
\hline 10 & I am proud of the work that I do (DE4*) & $\mathbf{0 . 7 9 5}$ & -0.096 & 0.063 \\
7 & My job inspires me (DE3*) & $\mathbf{0 . 7 9 1}$ & -0.034 & -0.056 \\
5 & I am enthusiastic about my job (DE2*) & $\mathbf{0 . 6 1 9}$ & 0.211 & -0.003 \\
9 & I feel happy when I am working intensely (AB3*) & $\mathbf{0 . 5 8 6}$ & -0.081 & 0.178 \\
8 & When I get up in the morning, I feel like going to work (VI3*) & $\mathbf{0 . 4 3 1}$ & 0.336 & -0.086 \\
16 & It is difficult to detach myself from my job (AB6) & $\mathbf{0 . 3 6 9}$ & 0.232 & -0.034 \\
2 & I find the work that I do full of meaning and purpose (DE1) & $\mathbf{0 . 3 2 6}$ & 0.204 & 0.176 \\
1 & At my work, I feel bursting with energy (VI1*) & -0.090 & $\mathbf{0 . 6 9 1}$ & -0.096 \\
4 & At my job, I feel strong and vigorous (VI2*) & 0.173 & $\mathbf{0 . 5 8 1}$ & -0.012 \\
3 & Time flies when I'm working (AB1) & 0.076 & $\mathbf{0 . 4 7 8}$ & 0.105 \\
12 & I can continue working for very long periods at a time (VI4) & -0.007 & $\mathbf{0 . 4 1 5}$ & 0.175 \\
6 & When I am working, I forget everything else around me (AB2) & -0.043 & $\mathbf{0 . 3 8 9}$ & 0.186 \\
14 & I get carried away when I'm working (AB5*) & 0.102 & -0.174 & $\mathbf{0 . 8 5 3}$ \\
17 & At my work I always persevere, even when things do not go well (VI6) & -0.110 & 0.241 & $\mathbf{0 . 5 7 4}$ \\
15 & At my job, I am very resilient, mentally (VI5) & -0.037 & 0.233 & $\mathbf{0 . 5 2 6}$ \\
11 & I am immersed in my work (AB4*) & 0.367 & 0.010 & $\mathbf{0 . 4 2 3}$ \\
13 & To me, my job is challenging (DE5) & 0.275 & -0.047 & $\mathbf{0 . 3 0 8}$ \\
\hline Total \% of variance explained & 36.7 & 3.8 & 2.9 \\
Cumulative \% of variance explained & 36.7 & 40.6 & 43.5 \\
\hline
\end{tabular}

$\mathrm{DE}$, dedication; $\mathrm{AB}$, absorption; VI, vigor, higher loading in each factor is denoted by bold; SN, serial number indicating the original order of the UWES. *Shortened version (Utrecht Work Engagement Scale-9 [UWES-9]).

Table 2. Factor loadings for the 9-item Nepalese version of the UWES (UWES-N-9) by exploratory factor analysis with the principal axis factoring method and promax rotation $(\mathrm{N}=438)$

\begin{tabular}{llrr}
\hline SN & Item & \multicolumn{2}{c}{ Factors } \\
\cline { 3 - 4 } & & \multicolumn{1}{c}{2} \\
\hline 11 & I am immersed in my work (AB4) & $\mathbf{0 . 7 7 7}$ & -0.046 \\
10 & I am proud of the work that I do (DE4) & $\mathbf{0 . 7 5 8}$ & 0.015 \\
9 & I feel happy when I am working intensely (AB3) & $\mathbf{0 . 7 4 7}$ & -0.089 \\
14 & I get carried away when I'm working (AB5) & $\mathbf{0 . 7 3 4}$ & -0.103 \\
7 & My job inspires me (DE3) & $\mathbf{0 . 6 1 0}$ & 0.120 \\
5 & I am enthusiastic about my job (DE2) & $\mathbf{0 . 5 0 9}$ & 0.319 \\
8 & When I get up in the morning, I feel like going to work (VI3) & 0.400 & $\mathbf{0 . 3 6 9}$ \\
4 & At my job, I feel strong and vigorous (VI2) & -0.014 & $\mathbf{0 . 8 1 5}$ \\
1 & At my work, I feel bursting with energy (VI1) & -0.105 & $\mathbf{0 . 6 0 0}$ \\
\hline Total \% of variance explained & 43.3 & 5.9 \\
Cumulative \% of variance explained & 43.4 & 49.2 \\
\hline
\end{tabular}

$\mathrm{DE}$, dedication; $\mathrm{AB}$, absorption; VI, vigor, higher loading in each factor is denoted by bold; $\mathrm{SN}$, serial number indicating the original order of the UWES.

The 9-item version with the three-factor structure fitted the data better than the 17-item three-factor structure. In addition, all items of the 9-item version had loadings $>0.4$ (Fig. 1), though the loading was somewhat low (0.47) for VI1, i.e., "At my work, I feel bursting with energy". Therefore, the three-factor model of the 9-item version was used for further analysis. 
Table 3. Results of confirmatory factor analysis: comparison of goodness-of-fit indices among one-factor, twofactor and three-factor models in the short and long versions of the Nepalese version of the Utrecht Work Engagement Scale (UWES-N) (N=438)

\begin{tabular}{lcccccccccc}
\hline Model & GFI & AGFI & PGFI & TLI & AIC & CFI & RMSEA & Chi-square & $d f$ & $p$ \\
\hline UWES-N-17 & & & & & & & & & & \\
1-factor $^{\text {a) }}$ & 0.88 & 0.85 & 0.69 & 0.86 & 510.67 & 0.88 & 0.07 & 442.67 & 119 & 0.00 \\
3-factor $^{\text {c) }}$ & $\mathbf{0 . 8 9}$ & $\mathbf{0 . 8 6}$ & $\mathbf{0 . 6 8}$ & $\mathbf{0 . 8 7}$ & $\mathbf{4 7 1 . 5 4}$ & $\mathbf{0 . 8 9}$ & $\mathbf{0 . 0 7}$ & $\mathbf{3 9 7 . 5 4}$ & $\mathbf{1 1 6}$ & $\mathbf{0 . 0 0}$ \\
UWES-N-9 $^{\text {a }}$ & & & & & & & & & & \\
1-factor $^{\text {a) }}$ & 0.92 & 0.88 & 0.55 & 0.89 & 180.45 & 0.92 & 0.10 & 144.45 & 27 & 0.00 \\
2-factor $^{\text {b) }}$ & 0.94 & 0.90 & 0.54 & 0.91 & 154.93 & 0.93 & 0.08 & 116.93 & 26 & 0.00 \\
3-factor $^{\text {c) }}$ & $\mathbf{0 . 9 5}$ & $\mathbf{0 . 9 1}$ & $\mathbf{0 . 5 1}$ & $\mathbf{0 . 9 3}$ & $\mathbf{1 3 2 . 1 1}$ & $\mathbf{0 . 9 5}$ & $\mathbf{0 . 0 7}$ & $\mathbf{9 0 . 1 1}$ & $\mathbf{2 4}$ & $\mathbf{0 . 0 0}$ \\
\hline
\end{tabular}

GFI, Goodness of Fit Index; AGFI, Adjusted Goodness of Fit Index; PGFI, Parsimony Goodness of Fit Index; TLI, Tucker Lewis Index; AIC, Akaike Information Criterion; CFI, Confirmatory Fit Index; RMSEA, Root Mean Square Error of Approximation; df, degree of freedom, better fit models denoted by bold letters.

a) All items measuring the three constructs loaded on one general work engagement factor. ${ }^{\text {b) }}$ Dedication and absorption items loaded on the first factor and vigor items loaded on the second factor. ${ }^{c}$ Each item loaded on a hypothesized three-factor model.

Regarding the UWES-N-9, the Cronbach's alpha coefficients were $0.83,0.60,0.78$ and 0.76 for the overall engagement, vigor, dedication and absorption subscales, respectively. The inter-item correlations were significant at $p<0.001$ and ranged from 0.16 to 0.55 , showing the homogeneity of the items. In addition, the correlation coefficient between each item score and a total scale or subscale ranged from 0.23 to 0.85 . These correlations were also significant at $p<0.001$. The Cronbach's alpha coefficients for the UWES-N-17 were $0.88,0.73,0.79$ and 0.72 for the overall engagement, vigor, dedication and absorption subscale, respectively. The inter-item correlations for the UWES-N-17 were significant at the $<0.001$ level and ranged from 0.16-0.57, indicating that the 17 items were homogeneous. In addition, the Cronbach's alpha coefficient for the absorption subscale of the long version was 0.75 after we replaced the original item with the revised item. The correlation between the original 17-item version and 9-item version was very high (0.95).

\section{Relationship with other well-being variables}

To investigate the construct validity of the UWES-N, the relationship with other indicators of well-being (job performance, job satisfaction, happiness, overall health and psychological distress) was tested using bivariate correlation analysis. The results showed that overall engagement was significantly negatively associated with psychological distress $(\mathrm{r}=$ $-0.35, p<0.01)$ but positively associated with overall health $(\mathrm{r}=0.24, p<0.01)$, job satisfaction $(\mathrm{r}=0.39$, $p<0.01)$, happiness $(\mathrm{r}=0.25, p<0.01)$ and job performance $(\mathrm{r}=0.38, p<0.01)$ (Table 4).

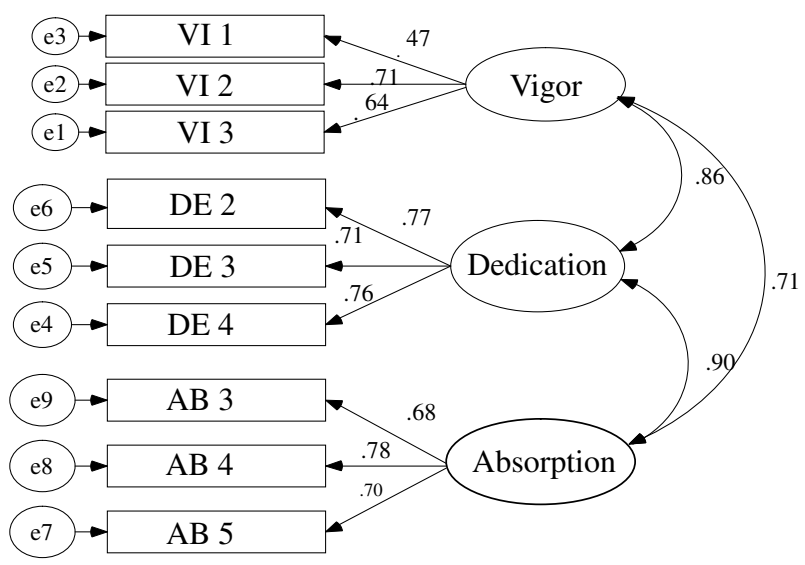

Fig. 1. Path diagram of the 9-item Nepalese version of the UWES (UWES-N-9), showing standardized coefficients from confirmatory factor analysis. VI, vigor; $\mathrm{DE}$, dedication; $\mathrm{AB}$, absorption.

\section{Characteristics of the UWES-N across demographic subgroups}

Table 5 reports the descriptive statistics of the UWES-N by demographic subgroups. Regarding age, a significant difference was found between groups in total score $(\mathrm{F}=10.89, p<0.001)$, vigor $(\mathrm{F}=11.87$, $p<0.001)$, dedication $(\mathrm{F}=7.87, p<0.001)$ and absorption $(\mathrm{F}=3.16, p<0.05)$. The post hoc Tukey's HSD test revealed that the higher age group (46-59 years) had significantly higher engagement compared with the $18-30$ years and $31-45$ years age groups $(p=<0.001)$. In terms of position, groups differed significantly in overall engagement $(\mathrm{F}=12.21, p<0.001)$, vigor $(\mathrm{F}=15.01$, $p<0.001)$, dedication $(\mathrm{F}=7.61, p<0.01)$ and absorption $(\mathrm{F}=3.16, p<0.05)$. The level of overall engagement 
Table 4. Correlation matrix for the 9-item Nepalese version of the UWES (UWES-N-9) and other validating variables $(\mathrm{N}=438)$

\begin{tabular}{|c|c|c|c|c|c|c|c|c|c|}
\hline & \multicolumn{9}{|c|}{ Correlations } \\
\hline & $\begin{array}{l}\text { Overall } \\
\text { engagement }\end{array}$ & Vigor & Dedication & Absorption & $\begin{array}{l}\text { Psychological } \\
\text { distress }\end{array}$ & $\begin{array}{l}\text { Overall } \\
\text { health }\end{array}$ & $\begin{array}{l}\text { Job } \\
\text { satisfaction }\end{array}$ & Happiness & $\begin{array}{l}\text { Job } \\
\text { performance }\end{array}$ \\
\hline Overall engagement & 1 & & & & & & & & \\
\hline Vigor & 0.84 & 1 & & & & & & & \\
\hline Dedication & 0.88 & 0.57 & 1 & & & & & & \\
\hline Absorption & 0.80 & 0.46 & 0.69 & 1 & & & & & \\
\hline $\begin{array}{l}\text { Psychological } \\
\text { distress }\end{array}$ & -0.35 & -0.26 & -0.38 & -0.25 & 1 & & & & \\
\hline Overall health & 0.24 & 0.23 & 0.23 & 0.14 & -0.31 & 1 & & & \\
\hline Job satisfaction & 0.39 & 0.31 & 0.41 & 0.27 & -0.33 & 0.31 & 1 & & \\
\hline Happiness & 0.25 & 0.21 & 0.27 & 0.15 & -0.29 & 0.28 & 0.36 & 1 & \\
\hline Job performance & 0.38 & 0.35 & 0.34 & 0.26 & -0.35 & 0.31 & 0.22 & 0.27 & 1 \\
\hline
\end{tabular}

All correlations are significant at the 0.01 level (2-tailed).

Table 5. Descriptive statistics, one-way ANOVA and multiple comparisons of the 9-item Nepalese version of the UWES (UWES-N-9) across demographic variables $(\mathrm{N}=438)$

\begin{tabular}{|c|c|c|c|c|}
\hline \multirow[t]{2}{*}{ Demographic variables } & \multicolumn{4}{|c|}{ Mean score (SD) } \\
\hline & $\begin{array}{l}\text { Overall } \\
\text { engagement }\end{array}$ & Vigor & Dedication & Absorption \\
\hline \multicolumn{5}{|l|}{ Age group (years) } \\
\hline 1) $18-30(n=284)$ & $4.81(0.85) * * *$ & $4.06(1.23) * * *$ & $5.06(1.03) * * *$ & $5.32(0.81) *$ \\
\hline 2) $31-45(n=98)$ & $4.75(0.89)$ & $4.02(1.23)$ & $4.96(1.01)$ & $5.26(0.91)$ \\
\hline 3) $46-59(n=56)$ & $5.36(0.81)$ & $4.91(1.24)$ & $5.59(0.77)$ & $5.60(0.69)$ \\
\hline Post hoc test & $1<3,2<3$ & $1<3,2<3$ & $1<3,2<3$ & $1<3,2<3$ \\
\hline \multicolumn{5}{|l|}{ Position } \\
\hline 1) General staff ( $n=368)$ & $4.78(0.90) * * *$ & $4.02(1.27) * * *$ & $5.02(1.06) * *$ & $5.30(0.86) *$ \\
\hline 2) Ward in charge $(n=46)$ & $5.29(0.58)$ & $4.81(0.99)$ & $5.51(0.57)$ & $5.55(0.54)$ \\
\hline 3) Supervisor $(n=24)$ & $5.41(0.44)$ & $5.04(0.70)$ & $5.58(0.47)$ & $5.61(0.46)$ \\
\hline Post hoc test & $1<2,1<3$ & $1<2,1<3$ & $1<3,2<3$ & $1<2$ \\
\hline \multicolumn{5}{|l|}{ Type of work } \\
\hline 1) Permanent $(n=154)$ & $5.04(0.89) * *$ & $4.41(1.27) *$ & $5.25(0.92) \mathrm{ns}$ & $5.46(0.81) \mathrm{ns}$ \\
\hline 2) Temporary $(n=262)$ & $4.77(0.86)$ & $4.02(1.24)$ & $5.01(1.06)$ & $5.29(0.84)$ \\
\hline 3) Daily wages $(n=22)$ & $4.82(0.81)$ & $4.06(1.19)$ & $5.19(0.90)$ & $5.21(0.73)$ \\
\hline Post hoc test & $1>2$ & $1>2$ & & \\
\hline \multicolumn{5}{|l|}{ Work experience (years) } \\
\hline 1) $0.1-10(n=307)$ & $4.77(0.86) * * *$ & $4.00(1.24) * * *$ & $5.02(1.04) * *$ & $5.29(0.86) \mathrm{ns}$ \\
\hline 2) $11-20(n=66)$ & $4.85(0.88)$ & $4.18(1.22)$ & $5.02(1.01)$ & $5.36(0.76)$ \\
\hline 3) $21-30(n=47)$ & $5.36(0.60)$ & $4.84(1.10)$ & $5.63(0.52)$ & $5.61(0.539$ \\
\hline 4) $31-39(n=18)$ & $5.31(4.87)$ & $4.94(1.41)$ & $5.48(1.15)$ & $5.51(0.99)$ \\
\hline Post hoc test & $1<3,1<4,2<3$ & $1<3,1<4,2<3,2<4$ & $1<3,2<3$ & \\
\hline
\end{tabular}

$* p$ value $<0.05 ; * * p$ value $<0.01 ; * * * p$ value $<0.001$. $\mathrm{SD}$, standard deviation; ns, nonsignificant. Only significant post hoc results are shown in the table.

was significantly higher for supervisors $(5.41 \pm 0.44$, $p=0.002)$ and wards in charge $(5.29 \pm 0.58, p=<0.001)$ compared with general staff $(4.78 \pm 0.90)$. However, no significant differences were found between supervisors and wards in charge $(p=0.84)$. Concerning work experience, the groups differed significantly in overall engagement $(\mathrm{F}=8.01, p<0.001)$, vigor $(\mathrm{F}=8.85$, $p<0.001)$ and dedication $(\mathrm{F}=5.93, p<0.01)$; however, the same was not found for absorption. Regarding type of work, the groups differed significantly in overall engagement $(\mathrm{F}=4.70, p<0.05)$ and vigor $(\mathrm{F}=4.72$, $p<0.01)$ but not in dedication and absorption. Nurses with a permanent job showed a higher level of overall engagement $(5.04 \pm 0.89, p=0.007)$ compared with 
nurses with a temporary job. The level of overall engagement was high among nurses with 21-30 years $(5.36 \pm 0.60, p=<0.001)$ and $31-39$ years $(5.31 \pm 1.01$, $p=0.04$ ) of experience compared with the group with one month to 10 years of work experience. Similarly, nurses with 21-30 years of experience showed a significantly higher level of overall engagement compared with nurses with 10-20 years of experience $(4.85 \pm 0.88, p=0.01)$. The results revealed no significant difference between nurses with 21-30 years and 31-39 years of experience.

\section{Discussion}

The current study examined the psychometric properties of the UWES in the Nepalese context in a sample of hospital nurses. Specifically, we examined the factorial validity, construct validity and internal consistency of the UWES-N.

To obtain the factor structure that best represents the UWES, exploratory factor analysis was used. The three factor solution for the 17-item version could not be interpreted meaningfully (Table 1), suggesting that participants in this study could not differentiate items in each dimension. This also might be the result of having many items measuring similar concepts. The 9-item version showed a two-factor structure (Table 2), with dedication and absorption factors merged into one factor. These results are in contrast with the basic theory ${ }^{3)}$, which assumes high correlation between vigor and absorption, suggesting that full immersion in one's activities is associated with high levels of energy and vice versa. The concept of work engagement is a new concept in Nepal; therefore, it clearly requires further research in this area taking into consideration different occupational group and both genders.

Although we found different factor structures using the EFA, we considered the concept of work engagement and employed the hypothesized threefactor solution when performing CFA to compare our study findings with other international studies. For the 17-item version, we compared the hypothesized three-factor model with the one-factor model. CFA revealed that the three-factor model fitted data better compared with the one-factor model. For the 9-item version, we compared the hypothesized three-factor model with the two-factor model (result from EFA) and one-factor model. Among the three models (onefactor, two-factor and three-factor models), the threefactor model had the best model fit. Furthermore, when comparing the 17-item and 9-item versions, the 9-item version with the three-factor model displayed the best model fit with the lowest chi-square statistic and AIC and the highest CFI and TLI. These findings are consistent with the findings of previous validation studies in which the three-factor UWES-9 exhibited stronger psychometric properties than the UWES-179,12, 22). However, these findings are inconsistent with a study conducted in Japan ${ }^{11}$, which reported that one-factor model was the best fitting model. However, high correlation among the three dimensions (vigor, dedication and absorption) supports the possibility of a one-dimensional nature.

Furthermore, the internal consistency of the 9-item three-factor UWES-N was sufficient according to the guidelines of Nummally and Bernstein ${ }^{23)}$, except for vigor (0.60). The alpha coefficient of 0.83 for the one-factor model was considerably higher. These results suggest that the 9-item UWES-N version is a reliable scale of work engagement in the Nepalese context. In addition, removing any of the items did not increase the alpha level, which underlines the importance of including all items in the scale. However, the low correlation $(0.29$ and 0.23$)$ of the item "At my work, I feel bursting with energy" (VI1) with the dedication and absorption subscales needs to be considered when using it in the Nepalese context.

Consistent with our expectation, work engagement was negatively associated with psychological distress and positively associated with health, job satisfaction, happiness and job performance. These findings are consistent with previous studies ${ }^{5,6,8,11)}$ that provided support for the construct validity of the UWES-N. However, because of the cross-sectional design of the current study, we cannot infer the causal direction of the relationships. Future research could design a longitudinal study to elucidate potential causal relationships.

When exploring demographic characteristics, older workers reported a significantly higher level of engagement. This is consistent with prior studies ${ }^{12)}$ in which work engagement was positively (though weakly) associated with age. Regarding position, supervisors and wards in charge showed higher levels of work engagement compared with general staff. This result is also consistent with a previous study $^{12)}$. In that study, educators, managers and police officers showed high levels of engagement, which was in contrast with a study conducted in China ${ }^{10)}$ in which support staff were more engaged compared with professional staff. At this moment, we do not have interventional evidence suggesting that educational methods or lifestyle habits would increase work engagement level. However, an empirical study ${ }^{24)}$ showed that higher occupational groups, like managers, have higher levels of engagement and share positive experiences with team members. Therefore, we believe that although the general staff in our study had low engagement levels, the higher engagement levels of supervisors and wards in charge may help 
increase the engagement level of their subordinate nurses. Similarly, permanent workers and workers with higher work experience showed higher engagement. Generally, permanent workers have higher salaries, more career opportunities and greater job security compared with temporary workers. Moreover, longer work experience might be associated with task identity. The abovementioned characteristics (high salary, carrier opportunity, job security, task identity and significance) are related to job resources at work $^{25)}$. According to the Job Demands-Resources model, higher job resources are related to higher work engagement. Thus, our results are consistent with the Job Demands-Resources model ${ }^{25)}$. However, a previous study ${ }^{26}$ found that salary and benefits were not the primary drivers of work engagement among nurses. This relationship needs to be investigated further. We can also hypothesize that higher engagement is related to higher salary in terms of reward. Although we lack information regarding salary in our sample, we recommend measuring the association of salary with the level work engagement in future studies.

Finally, limitations of this study needs to be addressed. Despite multisite recruitment and the high response rate of the study participants, the study sample came from a specific occupational field of female hospital nurses. Thus, the current study's results may not be generalized to other occupations. Future studies should examine the UWES-N among workers in different and perhaps male-dominated occupations.

\section{Conclusions}

In conclusion, this study confirmed that the 9-item version of the UWES-N has satisfactory psychometric properties and provided supportive evidence for its use in the Nepalese context. We hope that validation of the UWES-N is the first step to introducing the concept of work engagement in Nepal. It will not only promote a better understanding of work engagement in the Nepalese context but also inspire further researchers to explore different perspectives of work engagement and compare them with international studies.

Conflicts of interest: None declared.

\section{References}

1) Seligman MEP, Csikszentmihalyi M. Positive psychology. Am Psychol 2000; 55: 5-14.

2) Lopez SJ, Snyder CR. Positive psychological assessment: a handbook of models and measures. Washington, DC, US: American Psychological Association; 2006.

3) Schaufeli WB, Salanova M, Gonzalez-rom A V,
Bakker $\mathrm{AB}$. The measurement of engagement and burnout: a two sample confirmatory factor analytic approach. J Happiness Stud 2002b; 3: 71-92.

4) Bakker AB, Schaufeli WB, Leiter MP, Taris TW. Work engagement: an emerging concept in occupational health psychology. Work Stress 2008; 22: 187-200.

5) Mache S, Vitzthum K, Klapp BF, Danzer G. Surgeons' work engagement: influencing factors and relations to job and life satisfaction. Surgeon 2014; 12: $181-90$.

6) Rodriguez-Munoz A, Sanz-Vergel AI, Demerouti E, Bakker AB. Engaged at work and happy at home: a spillover-crossover model. J Happiness Stud 2014; 15: 271-83.

7) Bakken B, Torp S. Work engagement and health among industrial workers. Scand J Organ Psychol 2012; 4: 4-20.

8) Shimazu A, Schaufeli WB. Is workaholism good or bad for employee well-being? The distinctiveness of workaholism and work engagement among Japanese employees. Ind Health 2009; 47: 495-502.

9) Extremera N, Sánchez-García M, Durán MA, Rey L. Examining the psychometric properties of the Utrecht work engagement scale in two Spanish multi-occupational samples. Int J Select Assess 2012; 20: 105-10.

10) Fong TC-t, Ng S-m. Measuring engagement at work: validation of the Chinese version of the Utrecht work engagement scale. Int $\mathrm{J}$ Behav Med 2012; 19: 391-7.

11) Shimazu A, Schaufeli WB, Kosugi S, et al. Work engagement in Japan: validation of the Japanese version of the Utrecht work engagement scale. Appl Psychol Int Rev 2008; 57: 510-23.

12) Schaufeli WB, Bakker AB, Salanova M. The measurement of work engagement with a short questionnaire: a cross-national study. Educ Psychol Meas 2006; 66: 701-16.

13) Wild D, Grove A, Martin M, et al. Principles of good practice for the translation and cultural adaptation process for patient-reported outcomes (PRO) measures: Report of the ISPOR task force for translation and cultural adaptation. Value Health 2005; 8: 94-104.

14) South Asian Institute for Policy Analysis and Leadership (SAIPAL). Health Facility Mapping Survey 2009/2010. An Initiative to Institutionalize Health-GIS in Nepal. [Online]. 2010 [cited 2014 May 25]; Available from; URL: http://www.unfpa. org/sowmy/resources/docs/library/R088_DOHSNepal _2010_MappingSurvey.pdf

15) Kessler RC, Barber C, Beck A, et al. The world health organization health and work performance questionnaire (HPQ). J Occup Environ Med 2003; 45: $156-74$.

16) Scarpello V, Campbell JP. Job satisfaction: Are all the parts there? Pers Psychol 1983; 36: 577-600.

17) Libano MD, Llorens S, Salanova M, Schaufeli WB. Validity of a brief workaholism scale. Psicothema 
2010; 22: 143-50.

18) Kessler RC, Bakker PR, Clope LJ, et al. Screening for serious mental illness in the general population. Arch Gen Psychiatry 2003; 60: 184-9.

19) Arbuckle JL. AMOS Users Guide Version 3.6. Cichago: Small Waters Cooperation; 1997.

20) Schermelleh-Engel K, Moosbrugger H, Müller H. Evaluating the fit of structural equation models: test of significance and descriptive goodness-of-fit measures. Meth Psychol Res 2003; 3: 23-74.

21) Schmitt N. Uses and abuses of coefficient alpha. Psychol Assess 1996; 8: 350-3.

22) Seppala $P$, Mauno $S$, Feldt $T$, et al. The construct validity of the Utrecht work engagement scale: multisample and longitudinal evidence. J Happiness Stud 2009; 10: 459-81.

23) Nummally JC, Bernstein IH. Psychometric theory. 3rd ed. New York: McGrawhill; 1994.

24) Bakker AB, Emmerik HV, Euwema MC. Crossover of burnout and engagement in work teams. Work Occup 2006; 33: 464-89.

25) Bakker AB, Demerouti E. The job demands-resources model: state of the art. J Managerial Psychol 2007; 22: 309-28.

26) Rivera RR, Fitzpatrick JJ, Boyle SM. Closing the RN engagement gap: which drivers of engagement matter? J Nurs Admin 2011; 41: 265-72. 